\title{
Cleft palate-lateral synechia syndrome
}

INSERM

\section{Source}

INSERM. (1999). Orphanet: an online rare disease and orphan drug data base. Cleft palate-lateral synechia syndrome. ORPHA:2016

Cleft palate-lateral synechia syndrome (CPLS) is a congenital malformation syndrome characterized by the association of cleft palate and intra-oral lateral synechiae connecting the free borders of the palate and the floor of the mouth. CPLS is presumed to be inherited in an autosomal dominant manner. 